Discussion Paper No. 07-010

\title{
Educational Expansion
} and its Heterogeneous Returns for Wage Workers

Michael Gebel and Friedhelm Pfeiffer

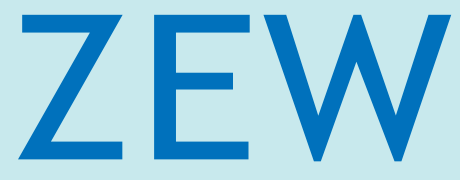

Zentrum für Europäische Wirtschaftsforschung $\mathrm{GmbH}$

Centre for European

Economic Research 
Discussion Paper No. 07-010

\title{
Educational Expansion and its Heterogeneous Returns for Wage Workers
}

\author{
Michael Gebel and Friedhelm Pfeiffer
}

Download this ZEW Discussion Paper from our ftp server:

ftp://ftp.zew.de/pub/zew-docs/dp/dp07010.pdf

Die Discussion Papers dienen einer möglichst schnellen Verbreitung von neueren Forschungsarbeiten des ZEW. Die Beiträge liegen in alleiniger Verantwortung der Autoren und stellen nicht notwendigerweise die Meinung des ZEW dar.

Discussion Papers are intended to make results of ZEW research promptly available to other economists in order to encourage discussion and suggestions for revisions. The authors are solely responsible for the contents which do not necessarily represent the opinion of the ZEW. 


\section{Non technical summary}

This paper examines the evolution of returns to education in the West German labour market in the period 1984-2004. Graduates from the period of educational expansion in the 1960s and 70s entered the labour market during the period of observation. With a lag, this educational expansion contributed to skill upgrading of the labour force. Our paper tries to contribute empirically to the question, whether this upgrading of schooling "devaluated" its monetary returns in the labour market in the longer run. Based on data from the German Socio-Economic Panel (GSOEP) we estimate returns to education over the past twenty years in West Germany differentiated by socio-economic characteristics to take into account demographic factors and the rise in female labour market participation.

A major challenge for empirical research on returns to education is that school choice involves complex decision processes. For instance, students may select themselves into secondary or post secondary education based on unobserved factors like ability, preferences, and parental household income. Students may choose to go to university because of their high skills and abilities. Students from a poor household may leave the educational system earlier because of financial constraints. As a result presumably there will be no single effect of an educational choice on wages but rather a whole distribution of such effects, i.e. returns vary across individuals. In order to tackle these issues we apply two estimation methods. On the one hand, Wooldridge's (2004) approach uses a set of observable control variables. On the other hand, Garen's (1984) control function approach requires an instrumental variable that influences the educational decisions but not the wage outcome.

For the population of workers from the GSOEP, we find that both approaches produce estimates of average returns to education that decrease until the late 1990s and increase significantly afterwards. According to the Wooldridge approach, returns to one additional year of education fell from 6.5 percent in 1984 to 4.9 percent in 1998. From 1998 onwards, we find increasing returns to education reaching a new local maximum of 6.4 percent in 2002 which is just below the overall maximum in 1984.

Regarding the gender aspects, the average returns to education seem to have been larger for women during the 1980s and early 1990s. However, the gap decreases over time which may be a consequence of increased participation of women. Furthermore, we find that the so called "baby boomer" cohort (workers born between 1958 and 1965) has the lowest average return to education compared to the cohort before and the one thereafter (the former is characterised by lower and the latter is characterised by sharply decreasing cohort sizes). However, according to our estimates the effect exists only at young ages and disappears when employees become older. 


\title{
Educational Expansion and its Heterogeneous Returns for Wage Workers
}

\author{
Michael Gebel* and Friedhelm Pfeiffer** \\ * University of Mannheim, MZES \\ ** University of Mannheim, ZEW Mannheim
}

\begin{abstract}
:
The paper examines the evolution of returns to education in the West German labour market over the last two decades. During this period, graduates from the period of educational expansion in the sixties and seventies entered the labour market and an upgrading of the skill structure took place. In order to tackle the issues of endogeneity of schooling and its heterogeneous returns we apply two estimation methods: Wooldridge's (2004) approach that relies on conditional mean independence and Garen's (1984) control function approach that requires an exclusion restriction. For the population of workers from the GSOEP, we find that both approaches produce estimates of average returns to education that decrease until the late 1990s and increase significantly afterwards. In the observation period, the gender gap in returns to education seems to vanish. Furthermore, we find that the so called "baby boomer" cohort has the lowest average return to education in young ages. However, this effect disappears when they become older.
\end{abstract}

\section{Keywords:}

Educational expansion, correlated random coefficient model, heterogeneous returns to education, conditional mean independence.

JEL-classification: J21, J24, J31

\section{Acknowledgements:}

Friedhelm Pfeiffer acknowledges financial support from the German Science Foundation under grants PF 331/2 ("Microeconometric Methods to Assess Heterogeneous Returns to Education") and PF 331/3 ("Wages, Rent-Sharing and Collective Wage Bargaining"). For constructive discussions we would like to thank Andreas Ammermüller, Gunhild Berg, Mila Beyer, Kathrin Göggel, Winfried Pohlmeier and Stephan Lothar Thompsen. All remaining errors are ours.

\section{Corresponding author:}

Friedhelm Pfeiffer, Centre for European Economic Research, P.O. Box 103443, D-68034 Mannheim. Tel.: +49-621-1235-150, E-mail: pfeiffer@zew.de 


\section{Introduction}

In Germany, a major expansion of post secondary education occurred during the 1960s and 70s. For instance, in the year 2005, 40 percent of the Germans in the age group of 25 to 30 held an upper secondary degree, compared to 23 percent of the 50 to 55 years old (Microcensus data, Statistisches Bundesamt, 2006). Even though this was a moderate expansion from an international perspective (Müller and Wolbers, 2003), it shares common goals. Among others, the expansion was issued to enhance individual well-being and equality of educational opportunity. A number of studies indicate that educational inequalities by social background have decreased in recent decades in Germany (Müller and Haun, 1994; Henz and Maas, 1995; SchimplNeimanns 2000) even though it seems as if the amount of educational inequality was still high (Dustmann 2004). Despite of an impressive amount of empirical research (see section 2 below) the longer run labour market impacts of educational expansion have not been studied systematically so far. This is somewhat surprising given the intensive discussion of for instance the negative impact of early tracking in the German educational system on the distribution of educational outcomes (see Schuetz et al., 2005).

Students of the period of educational upgrading entered the labour market later on and significantly raised the qualification structure of the workforce. For instance, in our sample of workers from West Germany, extracted from the German SocioEconomic Panel (GSOEP), average years of schooling increased from 11.2 years in 1984 to 12.3 years in 2004 . Our paper tries to contribute empirically to the question, whether the upgrading of schooling "devaluated" its monetary returns in the labour market in the longer run. We estimate heterogeneous returns to education over the past twenty years in West Germany differentiated by socio-economic characteristics to take into account demographic factors and the rise in female labour market participation.

Economists are interested in the influence of education on various socio-economic outcome variables, among them wages and unemployment risk. To assess these returns to education, selectivity into higher education during an expansion is of considerable interest. The level of education is generally chosen in a complex choice process (Card, 1999). Factors such as preferences, ability, financial constraints or differences in the quality of schools are usually unobserved by the researcher. If individuals self-select into education based on unobserved factors, this creates an endogeneity problem when estimating returns to education since the sample of individuals who make each schooling choice will not be random (Willis and Rosen, 1979). Furthermore, when estimating the standard Mincerian wage equation it is usually assumed that the return to schooling is homogenous, i.e. constant across individuals, though observed and unobserved factors can lead to heterogeneity in returns, i.e. returns vary across individuals. Thus, it follows that there is no single ef- 
fect of education but rather a whole distribution of individual effects (among others see Blundell et al., 2005; Heckman et al., 2006).

A significant part of the recent German literature is concerned with various data and methodological aspects of estimating returns to education in the presence of selectivity and heterogeneity (for recent surveys see Jochmann and Pohlmeier, 2004, Flossmann and Pohlmeier, 2006). Estimates for homogenous or constant returns to education for Germany reveal values between 5 and 14 percent, depending on the instruments used, whereas the average treatment effect of schooling has been estimated to be 8.9 percent for West German males in 1998 (Maier et al., 2004).

In this paper we try to contribute to the literature on educational expansion and its long run and heterogeneous returns. Our contribution is threefold. First, we investigate the evolution of heterogeneous returns to education in the labour market in the twenty year period from 1984 to 2004. The empirical assessment is based on data from the German Socio-Economic Panel (GSOEP). Second, we take the endogeneity and selectivity of school choice into account. A correlated random coefficient model is employed where the explanatory variable "year of schooling" is measured as a continuous treatment variable which can be correlated with unobserved heterogeneity. Identification is based on different assumptions. On the one hand, following Wooldridge (2004) we identify the average return to education via conditional mean independence assumptions. On the other hand, we implement a control function approach following Garen (1984) which uses exclusion restrictions to control for selection on unobservable heterogeneity. Third, the returns to education in West Germany are differentiated by demographic characteristics to take into account effects induced by female labour force participation and the rise of newborns until the sixties and its decline afterwards.

Our findings based on Wooldridge's (2004) conditional mean independence and Garen's (1984) control function approach are that both approaches produce estimates of average returns to education that decrease until the late 1990s and increase significantly afterwards. Using Wooldridge's approach, our results vary between 4.9 and 6.5 percent for the average partial effect of an additional year of schooling, which seems to be at the lower end of previous findings (Flossmann and Pohlmeier, 2006). Regarding the gender aspects, the average returns to education seem to have been larger for women during the 1980s and early 1990s. However, the gap decreases over time which may be a consequence of increased participation of women. Furthermore, we find that the so called "baby boomer" cohort has the lowest average return to education compared to the cohort before and the one thereafter (the former is characterised by lower and the latter by sharply decreasing cohort sizes). While this finding is in line with the literature on wages and cohort size (Macunovich, 1999), according to our estimates, the effect exists only at young ages and seems to disappear when employees become older. 
This paper is organized as follows. Section 2 discusses factors that influence returns to education over time. In Section 3, we develop the idea of heterogeneous returns to education in a correlated random coefficient model. We suggest different microeconomic estimation techniques: conventional approaches, Wooldridge's (2004), and Garen's (1984) approach. Section 4 describes the data set and variables used. Furthermore, first descriptive results for the evolution of educational attainment over time are presented. In section 5 , we compare estimation results differentiated by estimation techniques, gender and cohorts over time. Section 6 concludes.

\section{Educational Expansion, Wages and the Labour Market in West Germany}

Educational attainment started to increase in the 1960s in Germany leading with a lag to the upgrading of educational qualification in the labour market. In a standard economic supply and demand labour market framework, a rising supply of (high-) skilled workers may induce, ceteris paribus, a decline in the returns to education. A related concern is that educational expansion may have resulted in institutions digging deeper into the distribution of student abilities so that weaker students might have been admitted to higher education, leading to a decrease in the average productivity level of higher educated workers (for instance, Walker and Zhu 2005). Another concern is that teaching quality might have fallen because educational institutions were not able to provide the necessary quality for the rising quantities of students. This could have resulted in decreasing returns as well.

Besides of educational expansion there are other factors that influenced demand and supply conditions on German labour markets over the last two decades. Some important factors have been, for instance, birth cohort sizes, wage determination processes, increasing female labour market participation, and skill-biased technological change. West Germany, as well as many other western countries, experienced a demographic change due to a baby boom that peaked during the mid-1960s and sharply decreasing cohort sizes afterwards (see figure A.1). Changes in the number of births alter the supply of workers entering the market about 20 years later, i.e. in the period that we observe in the GSOEP data. If larger birth cohorts enter the labour market and substitution in production is limited between younger and older workers, ceteris paribus, a downward pressure on returns to education for labour market entrants arises (Macunovich, 1999; Freeman, 1979). In addition, there was fierce wage competition for entrants due to unemployment rates as high as ten percent in Germany. Compared to entrants, incumbent workers in Germany enjoy some protection against wage competition due to, for instance, strong unions and/or efficiency wage considerations (Franz and Pfeiffer, 2006).

Therefore, one might expect decreasing returns to education for the baby boom cohorts and increasing returns to education for individuals born after 1964 when cohort 
size started to decline sharply. Because large cohorts are absorbed gradually by the labour market when experience increases, according to our expectation, returns to education may have been lower mainly for labour market entrants. However, as a result of skill upgrading and globalisation the union wage policies may have lost part of its aggressiveness. Starting around 1992/93 wage inequality increased in Germany (Gernandt and Pfeiffer, 2006b) combined with rising returns to education.

The computer revolution that started around 1970 changed the organisation of labour away from routine manual tasks to non-routine analytical and creative tasks (Autor et al., 2006; Spitz-Oener, 2006). In this process of acceleration (Acemoglu, 2002), the demand for the high skilled created additional demand for high skilled workers, skill obsolescence increased for vocational skills, but not for general ones in Germany (Ludwig and Pfeiffer, 2006). These demand shifts towards analytical skills favoured presumably the high skilled and may be one additional reason for increasing returns to education.

Another channel that influences labour market supply and demand conditions is female labour force participation. In West Germany, the female participation rate has been rising during the last decades, leading to a catching-up process to men and competition for college slots and labour market positions. Based on the decreasing gender-gap in educational attainment and labour market participation, a convergence of gender-specific returns to education can be expected. For instance, Lauer and Steiner (2001) report homogeneous returns to education around 8 percent for men and 10 percent for women in the period from 1984 to 1997 based on the GSOEP. Ammermüller and Weber (2005) and Boockmann and Steiner (2006) find that gender differences in returns to education seem to fade away.

To sum up, we expect that supply side factors like educational expansion and increasing participation of women lower the returns to education (in a ceteris paribus sense) whereas supply side factors like decreasing cohort size and demand side factors like skill-biased technological change and workplace innovations increase the returns to education. In addition, the impact of educational expansion on wages will be formed by the process of wage determination, the regulation of labour as well as the rate of unemployment and active labour market policies. Over the twenty year period of observation, these factors have changed in West Germany and from a priori reasoning its impact on the returns to education seems to have been ambiguous. Therefore, we would like to investigate the evolution of the returns to education after the period of educational expansion in Germany differentiated by gender and birth-cohort. Furthermore, we concentrate on methodological issues of endogeneity of schooling and unobserved heterogeneity in returns to education. 


\section{Statistical Model and Identification}

\subsection{The Correlated Random Coefficient Model}

As a framework for the empirical assessment of the returns to education we employ the correlated random coefficient model (Heckman and Vytlacil, 2001):

$\ln Y_{i}=a_{i}+b_{i} S_{i}+u_{i}$ with $a_{i}=a^{\prime} X_{i}+\varepsilon_{a i}$ and $b_{i}=b^{\prime} X_{i}+\varepsilon_{b i}$

where the outcome variable $\ln Y_{i}$ is $\log$ wages and the explanatory variable $S_{i}$ is years of schooling of individual $i$. This equation may result from optimal schooling choice where education is determined by individual's observed and unobserved marginal benefits and the costs of schooling (see Card, 1999). The model has an individual-specific intercept $a_{i}$ and slope $b_{i}$ that may depend on observable variables $X_{i}$ and unobservable heterogeneity $\varepsilon_{a i}$ and $\varepsilon_{b i}$. The heterogeneity components capture influences from gender, family background, age, preferences, ability, etc. such that $a_{i}$ and $b_{i}$ represent random coefficients. In addition, we do not assume that $b_{i}$ and $S_{i}$ are independent, so that $a_{i}$ and $S_{i}$ as well as $b_{i}$ and $S_{i}$ can be correlated (Wooldridge, 2004). For example, since individuals with higher benefits from education are more likely to participate longer in education, the returns to education $b_{i}$ may in general be correlated with $S_{i}$ if variation in unobserved (to the econometrician) benefits implies positive self-selection. In this case, the schooling variable is influenced by its own coefficient, yielding an endogeneity problem.

We are interested in estimating the heterogeneous effects of $S_{i}$ on $\ln Y_{i}$ represented by $b_{i}$ in the structural model. In this model, the return to education varies across individuals in both, observable heterogeneity in returns $X_{i}$ and unobserved individualspecific returns to schooling $\varepsilon_{b i}$. Hence, there is no single parameter for the return to schooling, i.e. there is a distribution of effects across individuals. The distribution of the returns to education can be summarized with the average partial effect (APE) that measures the average return for an additional year of education in the expansion process for a randomly chosen individual of the population:

$$
E(\partial \ln Y / \partial S)=E\left(b_{i}\right)=\beta
$$

$\beta$ represents the average treatment effect for the case of a continuous treatment variable (Flossmann and Pohlmeier, 2006; Wooldrigde 2004). The earnings equation (1) allows the considering of the problem of homogeneous and heterogeneous returns to education in a common framework. If returns to education are homogenous, the outcome equation can be re-written as the classical Mincer-type of earnings function (Blundell and Costa Dias, 2000): 
$\ln Y_{i}=a^{\prime} X_{i}+\bar{b} S_{i}+\varepsilon_{a i}+u_{i}$

where $\bar{b}$ is the common return to education. Traditionally, unobserved heterogeneity enters exclusively the intercept of the wage equation but not the slope coefficient. ${ }^{1}$ One appealing feature of our model (1) is that variation in unobserved heterogeneity affects the slope as well, i.e. unobserved heterogeneity influences the wage effect of education.

\subsection{Potential Pitfalls of Conventional Approaches}

When estimating (1) by OLS, there are three potential sources of a bias due to unobservable variables inducing a non-zero correlation between schooling and the error term in the outcome equation (see Blundell et al., 2005; Heckman et al., 2006). First, if individuals with high absolute earnings capacity both acquire more education and

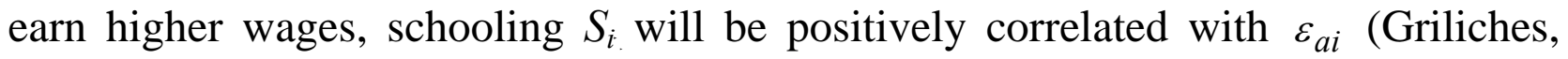
1977). This ability bias induces an upward bias in the estimated average return. Second, there may be a measurement error in the schooling variable $S_{i}$ inducing a downward biased in the case of classical measurement error (Griliches, 1977). Third, there can be a return bias if individuals differ in their relative earnings capacity and act upon their comparative advantage when choosing their level of education (Willis and Rosen, 1979). The direction of this bias is less clear in the case when returns are heterogeneous (Blundell et al., 2005). If returns to education are by definition homogeneous, return bias is absent.

The majority of the literature on the return to schooling uses instrumental variables (IV) methods to handle the endogeneity problems. To this end, the instrumental variable has to be correlated with schooling and should be uncorrelated with unobserved individual earning capacities. For instance, Lauer and Steiner (2001) estimate homogeneous returns to education for Germany by IV-methods using different family background variables as instruments. The results depend on the instruments used. The estimated returns to education vary between 6.6 and 14.8 percent. Jochmann and Pohlmeier (2004) use different instruments in the case of heterogeneous returns as for example the number of siblings, secondary school density or the unemployment rate at graduation. Again, the results vary to some degree with the chosen instruments.

However, when schooling is correlated with unobserved individual heterogeneity in returns to education as assumed in the correlated random coefficient model, standard IV methods may fail (Heckman and Li, 2004). In this case, one may redefine the parameter of interest as the Local Average Treatment Effect (LATE) in the sense of

\footnotetext{
${ }^{1}$ Note that there might still be endogeneity problems, if the unobserved general individual earnings capacity $\varepsilon_{a i}$ is correlated with $S_{i}$
} 
Angrist et al. (1996). For a binary treatment variable, LATE estimates the average returns to schooling for compliers, i.e. individuals who were induced to change their participation status by a change in the instrument. For example, Ichino and WinterEbmer (1998) as well as Becker and Siebern-Thomas (2001) estimate LATE for Germany using different family background variables as instruments. Since each instrument implies its own LATE and the group of compliers cannot be identified without further assumptions, this may be regarded as a drawback. However, LATE is especially interesting when school reforms are used as instruments since LATE measures the returns to schooling for those who changed their level of schooling because of the reform. With this approach, Pischke and van Wachter (2006) find rather low marginal returns to education in Germany.

In our empirical analysis, we contrast two methods that do not suffer from biases like standard OLS and IV techniques because they try to capture both heterogeneity and endogeneity. They rely on different identifying assumptions: Wooldridge's (2004) conditional mean independence (CMI) approach and Garen's (1984) control function (CF) approach.

\subsection{Wooldridge's (2004) Conditional Mean Independence (CMI) Approach}

The first identification strategy considered relies heavily on conditional moment independence assumptions. Following Wooldridge (2004), we can identify APE with the following two assumptions as far as the linear outcome equation (1) holds:

$$
\begin{aligned}
& E\left(\ln Y_{i} \mid a_{i}, b_{i}, S_{i}, X_{i}\right)=E\left(\ln Y_{i} \mid a_{i}, b_{i}, S_{i}\right)=a_{i}+b_{i} S_{i} \\
& E\left(S_{i} \mid a_{i}, b_{i}, X_{i}\right)=E\left(S_{i} \mid X_{i}\right) \text { and } \operatorname{Var}\left(S_{i} \mid a_{i}, b_{i}, X_{i}\right)=\operatorname{Var}\left(S_{i} \mid X_{i}\right)
\end{aligned}
$$

where the elements of $X_{i}$ are suitable proxy variables for the observed and unobserved heterogeneity, i.e. the $X_{i}$ should be good enough predictors of $S_{i}$. The first assumption postulates that the vector $X_{i}$ is redundant given $S_{i}$ and $\left(a_{i}, b_{i}\right)$ in the structural conditional expectation (4). This identification assumption obviously holds since the control variables $X_{i}$ enter the earnings function through $a_{i}, b_{i}$, and $S_{i}$ only (Maier et al., 2004). The second assumption is a redundancy condition of the form that both heterogeneity terms $a_{i}$ and $b_{i}$ are redundant in the first two conditional moments of the schooling variable $S_{i}$ conditional on a set of covariates $X_{i}$. This latter and strongest assumption requires a differentiated set of variables that control sufficiently for observable and unobservable heterogeneity. These conditional moment independence (CMI) conditions are a weaker form of conditional independence assumptions (CIA) (Wooldridge, 2002: 607).

Wooldridge (2004: 23) shows that his CMI approach can be interpreted in the binary treatment case as a weighting matching estimator. In contrast to methods that rely on exclusion restrictions like instrumental variable approaches and control functions, 
APE is identified without any exclusion restriction. Based on assumptions (4) and (5) Wooldridge (2004) derives the following estimator for APE:

$$
\hat{\beta}=\frac{1}{N} \sum_{i=1}^{N}\left(\left(S_{i}-\hat{E}\left(S_{i} \mid X_{i}\right)\right) \ln Y_{i} / \hat{\operatorname{Var}}\left(S_{i} \mid X_{i}\right)\right)
$$

Because $\ln Y_{i}, S_{i}$ and $X_{i}$ are observable, one needs to estimate $E\left(S_{i} / X_{i}\right)$ and $\operatorname{Var}\left(S_{i} / X_{i}\right)$. The difficulty arises from consistently estimating $E\left(S_{i} / X_{i}\right)$ and $\operatorname{Var}\left(S_{i} / X_{i}\right)$. Since $S_{i}$ is nonnegative, simple linear models have shortcomings. Therefore, we employ a generalized linear model (GLM) with a Poisson distributional assumption for years of schooling $S_{i}$ :

$$
E\left(S_{i} \mid X_{i}\right)=e^{\gamma^{\prime} X_{i}} \text { and } \operatorname{Var}\left(S_{i} \mid X_{i}\right)=\sigma^{2} e^{\gamma^{\prime} X_{i}}
$$

This specification guarantees positive estimates of both conditional mean and variance. $^{2}$ A consistent estimator of $\sigma^{2}$ is obtained as the mean of squared Pearson residuals. Since analytical standard errors have not been developed so far, standard errors of APE are bootstrapped.

\subsection{Garen's (1984) Control Function (CF) Approach}

Garen (1984) proposed a possible alternative solution to the random coefficient estimation problem - called the control function (CF) approach - that is similar to the two-step procedure commonly used to correct for traditional selectivity bias (Heckman, 1978). While the standard IV approach does generally not identify APE in the heterogeneous returns context the CF approach does. The CF approach is implemented by simultaneously modelling both the process of educational attainment and the process of generating wages. Hence, an explicit model of the schooling selection process which relates the rule for assigning individuals to treatment to the potential treatment outcomes is required:

$$
S_{i}=c^{\prime} X_{i}+d Z_{i}+v_{i} \text { with } E\left(v_{i} \mid Z_{i}, X_{i}\right)=0
$$

where both $X_{i}$ and $Z_{i}$ influence the educational decision and $v_{i}$ represents an usual error component, incorporating unobserved components which determine the choice of education. $Z_{i}$ is an exclusion restriction, i.e. it should have no correlations with unobserved heterogeneity in the wage equation. The error terms $v_{i}, \varepsilon_{a i}$ and $\varepsilon_{b i}$ are

\footnotetext{
${ }^{2}$ Contrary to the standard variance assumption of equality between the conditional variance and the mean we specify in (7) the weaker Poisson GLM variance assumption that allows the variance-mean ratio to be any positive constant (Wooldridge, 2002)
} 
normally distributed with zero means, positive variances and are possibly correlated with each other. ${ }^{3}$

Following Garen (1984) one can formulate an augmented wage equation of the form:

$\ln Y_{i}=a_{i}+\beta S_{i}+\gamma_{1} v_{i}+\gamma_{2} v_{i} S_{i}+w_{i}(9)$

where $\gamma_{1} v_{i}$ and $\gamma_{2} v_{i} S_{i}$ are the control functions with $\gamma_{1}=\operatorname{cov}\left(\varepsilon_{a i}, v_{i}\right) / \operatorname{var}\left(v_{i}\right)$ and $\gamma_{2}=\operatorname{cov}\left(\varepsilon_{b i}, v_{i}\right) / \operatorname{var}\left(v_{i}\right)$. Once these terms are included in the outcome equation (and implicitly subtracted from its error term), the error term $w_{i}$ has all the desirable properties, i.e. it is orthogonal to all of the regressors in the new equation: $E\left(w_{i} \mid X_{i}, S_{i}, v_{i}\right)=0$ (Heckman and Robb, 1985).

This model can be estimated using a generalization of the standard two-step approach. In the first step an estimation of the schooling choice is used to construct the control functions that are included as additional regressors in the augmented wage equation in the second step. The estimated coefficients of $v_{i}$ and $v_{i} S_{i}$ provide information about the selection on the unobserved absolute earnings capacity term and about selection on comparative earnings capacity, respectively. If an individual attains a higher (lower) level of education than expected by our model the value of $v_{i}$ is positive (negative). For example, if the coefficient $\gamma_{1}$ of the first control function is positive, this implies that the unobserved factors that lead to educational 'overachievement' (positive $v_{i}$ ) have a positive impact on earnings. The sign of the coefficient $\gamma_{2}$ of the second control function describes how this effect changes for increasing levels of education. Following the comparative advantage hypothesis (Willis and Rosen, 1979), we would expect that $\gamma_{2}$ is positive, i.e., those with unexpectedly large amounts of schooling (positive $v_{i}$ ) tend to earn more than the others in higher education (Garen, 1984). Based on their higher unobserved marginal returns they select into higher education according to their comparative advantage.

\section{Data and Descriptive Analysis}

\subsection{Sample Selection}

For the analysis, we use 21 waves of the German Socio-Economic Panel Study (GSOEP) that collects longitudinal representative micro-data on persons, households and families on a yearly basis. GSOEP contains information on various socioeconomic factors like education, employment and earnings. In addition to annually collected information, GSOEP retrieves some retrospective information about fam-

\footnotetext{
${ }^{3}$ This trivariate normality assumption can be weakened to the condition that conditional expectations of the unobserved earning components $\varepsilon_{a i}$ and $\varepsilon_{b i}$ are linear in the residual of the selection equation (Blundell et al., 2005).
} 
ily background, among others. We include new samples from 1998 and 2000. Due to missing value problems on educational attainment and lack of comparability, foreign-born individuals were excluded from the sample. Furthermore, for the purpose of comparability, the analysis is restricted to West German citizens because of economic differences and discrepancies in the schooling system between West and East Germany. Self-employed workers are excluded from the sample since they are exposed to different earnings-generating mechanisms.

The resulting sample is restricted to full-time dependent workers aged between 25 and 60, defined as individuals working 30 hours or more per week. After eliminating all units with missing values in any of the variables considered we obtain a final sample size that ranges from 1,535 observations in 1984 to 3,958 in 2000.

The dependent variable is the natural logarithm of real earnings per hour worked. The real gross hourly wage is obtained by dividing the monthly nominal gross wage in the month preceding the date of the interview by the number of hours worked. Hence, the focus lies exclusively on the direct monetary returns to education. For the sake of comparability with economic studies on monetary returns to education, we measure school careers in years attended rather than educational degrees completed. Linearity in the earnings equation implies that each year of schooling yields an identical return to education, irrespective of the level of education. GSOEP contains information on the highest completed level and type of education for each individual. The measure of years of schooling is derived by attaching a standard number of years to the highest educational level (cp. table A.1). However, it does not necessarily reflect the actual number of years attended since a person may need less or more than standard time to complete her education. ${ }^{4}$

As standard control variables, gender and individual's age (in linear and quadratic terms) are included. We use age variables instead of potential labour market experience because the latter might be endogenous with respect to schooling. To justify the conditional moment independence assumptions we make use of a set of family background information that is covered by recall questions and that is available for a sufficient number of persons in each wave considered. Family background characteristics should proxy for the parental influence on educational attainment and later employment carriers.

In detail, we distinguish between educational and occupational social background. The measure for parents' education follows the CASMIN educational classification which has the advantage to combine information on the highest school degree and the highest vocational degree of the parents (Erikson and Goldthorpe, 1992). The CASMIN categories have been summarized in five categories for fathers and in a dummy-variable for mother's higher education (cp. table A.1). Parents' education

\footnotetext{
${ }^{4}$ For an analysis of the issue of over education in workers from different educational degrees see Maier et al. (2004).
} 
may indicate ability differences due to genetic endowments as well as the formation of skills in early childhood to improve educational performance, e.g. with verbal training during childhood or practical help with school work (Erikson and Jonsson, 1996). Finally, education may positively influence parents' taste and perception of what is the best educational career for their children (Dustmann, 2004).

There are four categories of parents' occupational position (cp. table A.1). These categories should proxy for the economic circumstances of the family which affect educational choice by influencing costs of schooling. A further proxy for costs of schooling is the dummy variable "rural socialisation" that is similar to other variables in the literature measuring proximity to college (see for instance Card, 1995; Becker and Siebern-Thomas, 2001).

To implement the control function approach we use the number of siblings as an exclusion restriction and assume that it satisfies the two conditions for valid instrumental variables (Wooldridge, 2002). First, a number of authors (for instance Becker and Tomes, 1976, Hanushek, 1992) hypothesize a positive correlation between the number of siblings and individual educational attainment even after controlling for other family background characteristics. Parents try to optimally allocate financial and non-financial resources to their children who compete for the attention and resources of their parents. Therefore, educational achievement and total family size might be negatively related under the constraint of limited educational resources.

Second, the instrumental variable should be uncorrelated with unobserved individual's earnings capacities, i.e., the number of siblings should not have an effect on income other than the indirect effect transmitted over educational attainment. Because we control for a set of other family background variables like parents' education, occupation and the place of socialisation we do not expect a non-negligible, systematic and independent effect of the number of siblings on earnings. In the case of Wooldridge's (2004) CMI approach the number of siblings serves as a further control variable. To estimate the causal effect of education on income we do not control for variables that might be a consequence of education like actual family status, economic sector, tenure, etc. Table A.1 gives an overview of the variables and its definitions. Table A.2 provides summary statistics for key individual level variables in selected years.

\subsection{Trends in educational attainment by sex and birth cohort}

During the past two decades the educational composition of the West German labour force has changed. Figure 1 summarizes changes in the gender-specific educational attainment of the West German labour force, aged 25 to 60 years, between 1984 and 
2004 using GSOEP. ${ }^{5}$. As this figure shows, the mean number of years of schooling has steadily increased for both men and women which points to an upward shift of the qualification structure during this period. For men (women), the increase was from 11.6 (10.8) years in 1984 to 12.4 (12.2) years in 2004. Women are catching up constantly so that in recent years the female average educational attainment becomes similar to the male educational attainment.

A similar analysis by birth cohorts reveals the same trends in educational attainment. Figure 2 displays average years of schooling for selected birth cohorts, as observed at roughly the same age of 31 to 38 years in different years. For women, we observe a proportional increase in years of schooling as we move to younger birth cohorts. For example, the birth cohort of people born in 1942-49 has an average educational attainment of 11.1 years for women and 12 years for men. The gender gap in years of schooling vanishes for the birth cohort of people born in 1966-73.

Figure 1: Average years of education by gender, 1984-2004 (individuals aged 25-60)

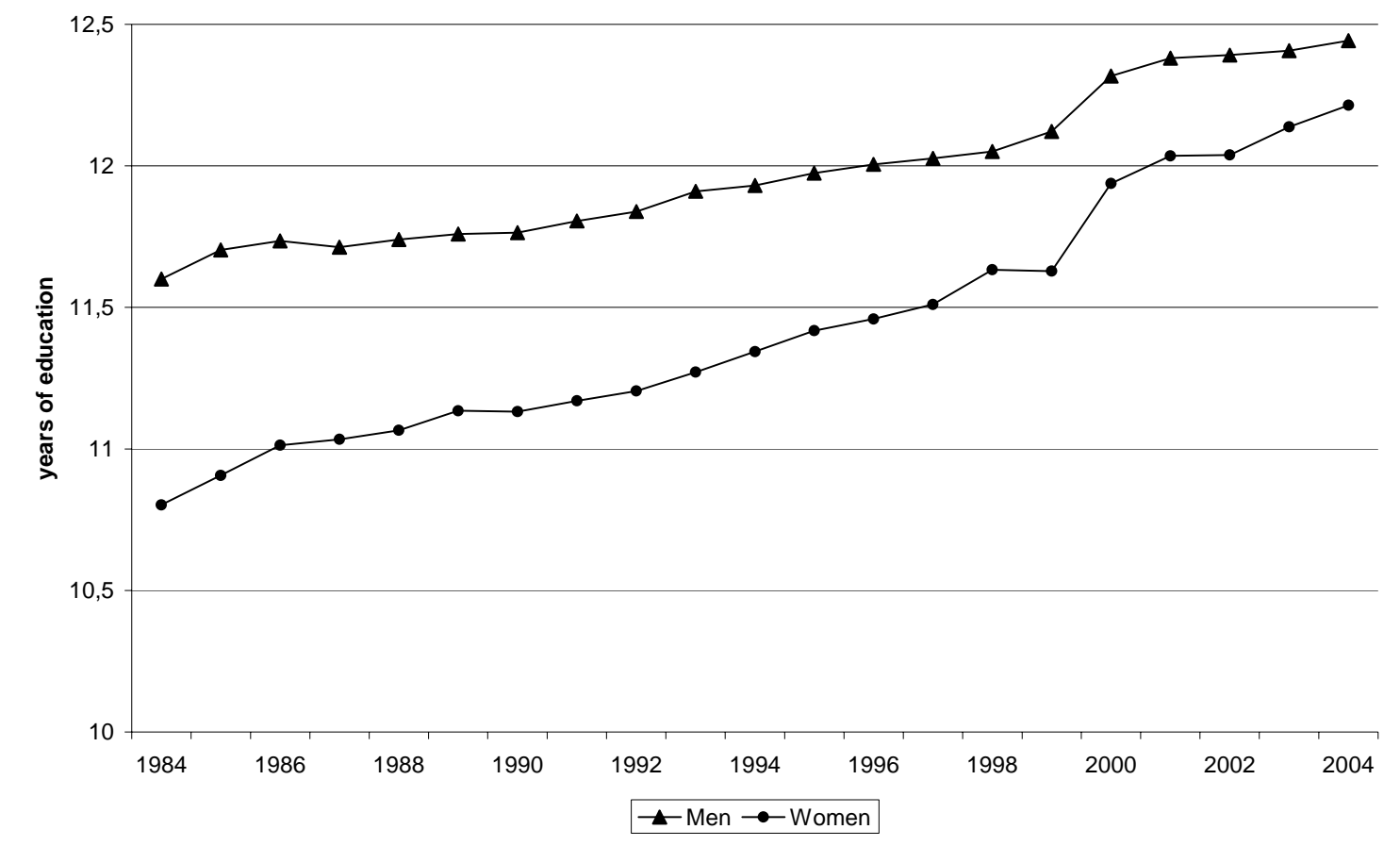

Source: SOEP (1984-2004); own computations.

\footnotetext{
${ }^{5}$ All estimates in figure 1 as well as in the following figure 2 are based on calculations with the weights provided by GSOEP in order to reflect population totals.
} 
Figure 2: Average years of education by gender and birth cohorts, measured at roughly the same age of 31-38 years.

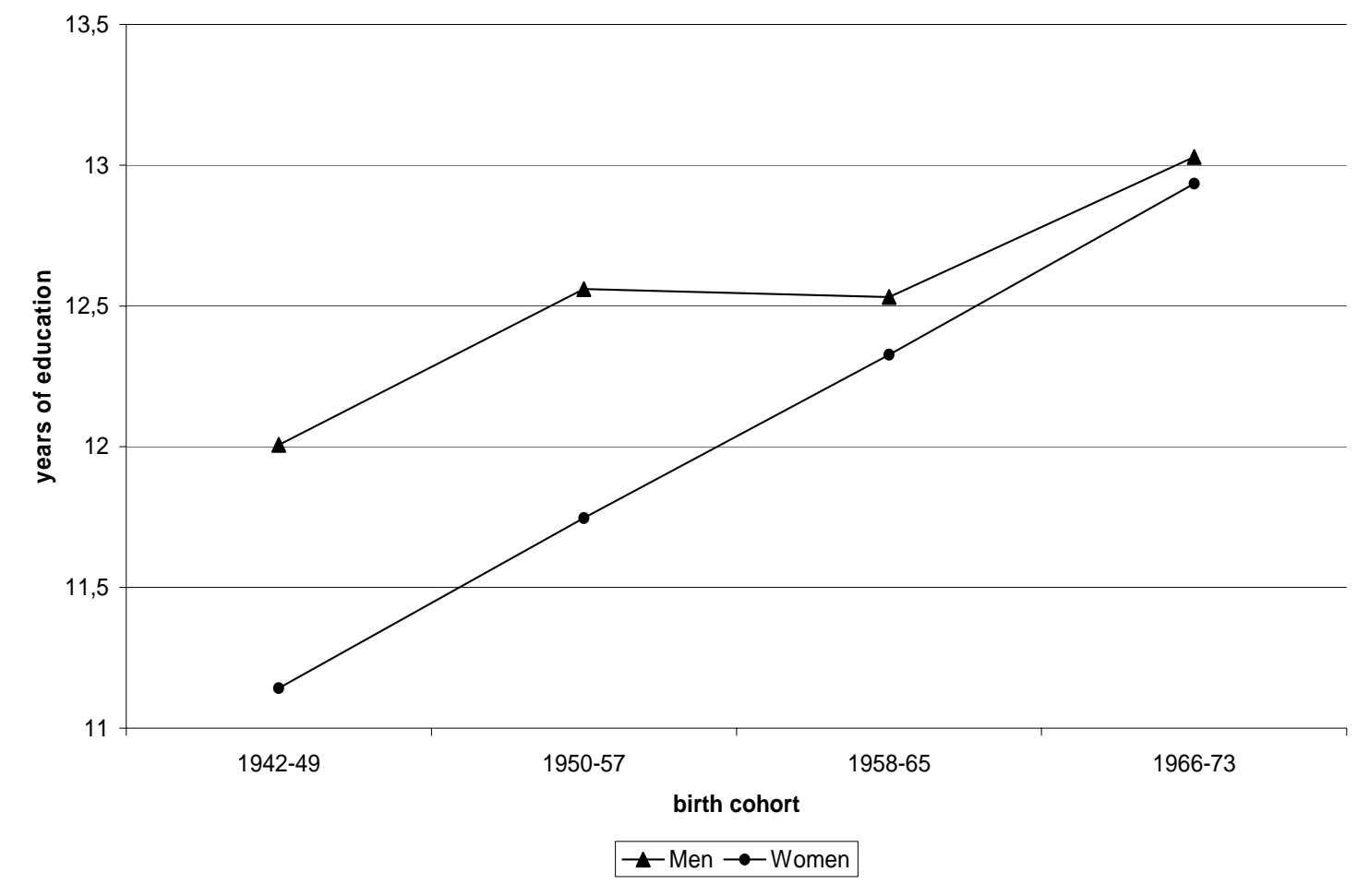

Source: SOEP (1984-2004); own computations.

Remark: Cohort 1966-73 is observed in 2004, cohort 1958-65 in 1996, and cohort 1950-57 in 1988 all at age 31-38. Cohort 1942-49 is observed in 1984 at age 35-42 reflecting only a small deviation in age from the other birth cohorts.

\section{Estimation Results}

\subsection{Comparison of Results from Different Estimation Techniques}

Figure 3 compares the evolution of three different estimates of individual returns to education in West Germany during the period 1984 to 2004 (for detailed estimation results and standard errors see table A.3). As a benchmark, figure 3 contains results from an OLS regression with years of schooling controlling for age in linear and squared functional form on log wage. Furthermore, the APE from the conditional mean independence (CMI) approach and from the control function (CF) approach are illustrated. With OLS we find a slight downward trend in the evolution of returns to schooling until the late 1990s. The returns to one additional year of education fell from 7.3 percent in 1984 to 5.4 percent in 1998. From 1998 onwards, we find increasing returns to education reaching a new local maximum of 6.7 percent in 2002. The estimates until 1998 are in line with the findings of Franz (2006), Ammermüller and Weber (2005) or Lauer and Steiner (2001). To the best of our knowledge, increasing returns to education starting around 1998 had not been documented so far. 
Figure 3: Average Partial Effect, 1984-2004: OLS, CMI, and CF compared

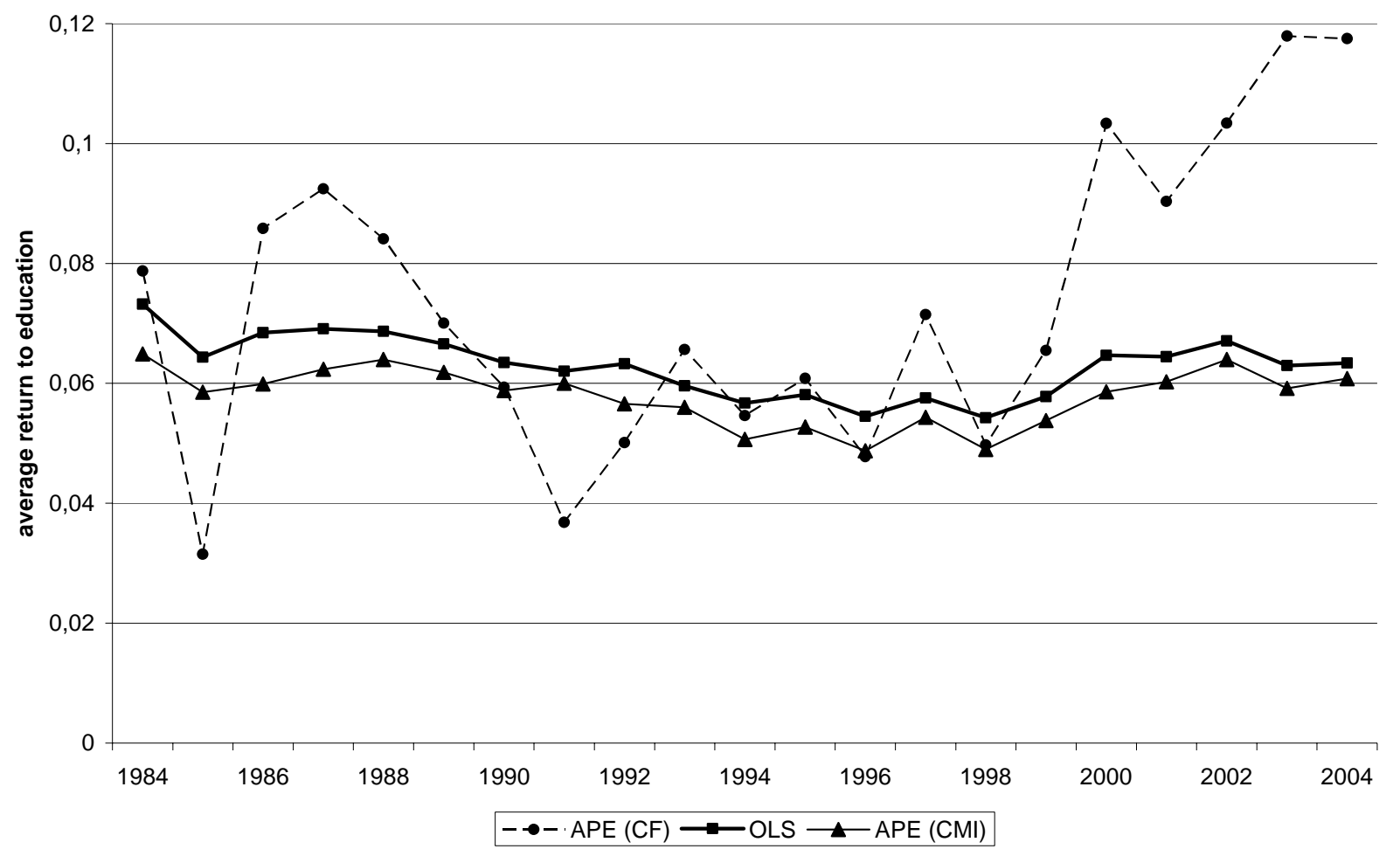

Source: SOEP (1984-2004); own computations.

Interestingly, the APE estimated under conditional moment independence (CMI) follows a fairly similar evolution pattern over time. However, there are differences. First: the estimated APE is always lower than standard OLS, between 0.5 and 1 percentage points. According to our interpretation this difference reflects the potential ability bias from OLS estimates. Taking into account the heterogeneity of returns to education and controlling for family background variables the CMI approach controls for positive ability bias to a certain degree. Second: although OLS and APE estimates are comparable over time, their content varies. APE measures the average of the distribution of heterogeneous returns, whereas OLS measures an individually constant homogenous return to education. Compared to the literature, our estimate of the APE seems to be rather low. Maier et al. (2004), for instance report an estimated APE of 8.7 percent for the year 1999 for German male workers.

The control function (CF) approach has been implemented in a two-stage estimation procedure. The first stage involves the educational attainment selection equation and can be used to test for the validity of the instrumental variables. According to our findings the number of siblings has a partially negative influence on educational attainment, holding constant other family background characteristics (cp. table A.4). This seems to be in line with the literature mentioned above. A regression that includes the number of siblings in a simple OLS log-wage equation together with other family background variables was insignificant suggesting that the number of siblings seems to be a reasonable exclusion restriction. The coefficient of the control 
function for the selection on unobserved absolute earnings capacity is positive, although it decreases over time (cp. table A.4) and is never significant. This is only weak evidence for a positive ability bias. Probably, the information regarding educational background of the family proxies already well for the absolute earnings capacity.

The coefficient of the control function for the selection on comparative earnings capacity is always negative. This contradicts the comparative advantage hypothesis. In our sample we find that those with unexpected high amounts of schooling have lower marginal returns to education. Individuals, who seem to rather not have gone to higher education, but have anyway, have done worse. The effect is significant in the period from 1984 to 1989 and from 2000 onwards. In these years, we find negative selection on unobservable returns, which may confirm the zero returns to education findings from Pischke and van Wachter (2005).

The evolution pattern of the estimated APE under CF approach deviates substantially from the CMI results. First, the yearly estimates derived from the CF approach are more volatile and less precise (the standard errors are higher). Detailed tests show that the deviations are usually not significant during the 1980s and the initial fluctuations (see figure 3) might be a consequence of lower numbers of observations. Second, there is a stronger increase of the APE after 1998 compared to the CMI approach. In 2004, the APE is 12 percent, which is in line with some recent IV studies for Germany, Flossmann and Pohlmeier (2006). From a methodological point of view the deviations reflect differences in the identification strategies. From a substantive point of view the discrepancy during the last years could be a hint for rising selection on unobservables, which the CF approach controls for (Taber, 2001). This coincides with the significant effects for the second control function from 2000 onwards.

To summarize our findings so far: Independently of the method used, the returns to education (APE) were fairly constant during the 1980s and 1990s in (West) Germany. Despite of a continuing upgrading of educational qualification they started to increase from 1998 onwards (see figure 1). This surprising finding seems to be line with rising wage inequality in Germany that started around 1994 (see Gernandt and Pfeiffer, 2006b).

\subsection{Gender and Cohort Effects}

The following analysis differentiates gender and birth cohorts in the returns to education since it might be helpful for understanding the recent increase in the APE. The comparison rests on the CMI approach because it produces lower standard errors than the CF approach. For women, we find a robust decline in returns to education until the late 1990s: the average return to an additional year of education in the population of women from the GSOEP declined from 8.5 percent in 1984 to about 
4.9 percent in 1996 (cp. figure 4, for details table A.5). This robust finding can, at least in our interpretation, be best understood in terms of female educational expansion and rising participation, a traditional supply side interpretation. This enhanced wage competition and pressure on the APE. However, since 1999 the APE is increasing again for women, as it is for men.

Figure 4: Average Partial Effect by gender, 1984-2004: CMI approach

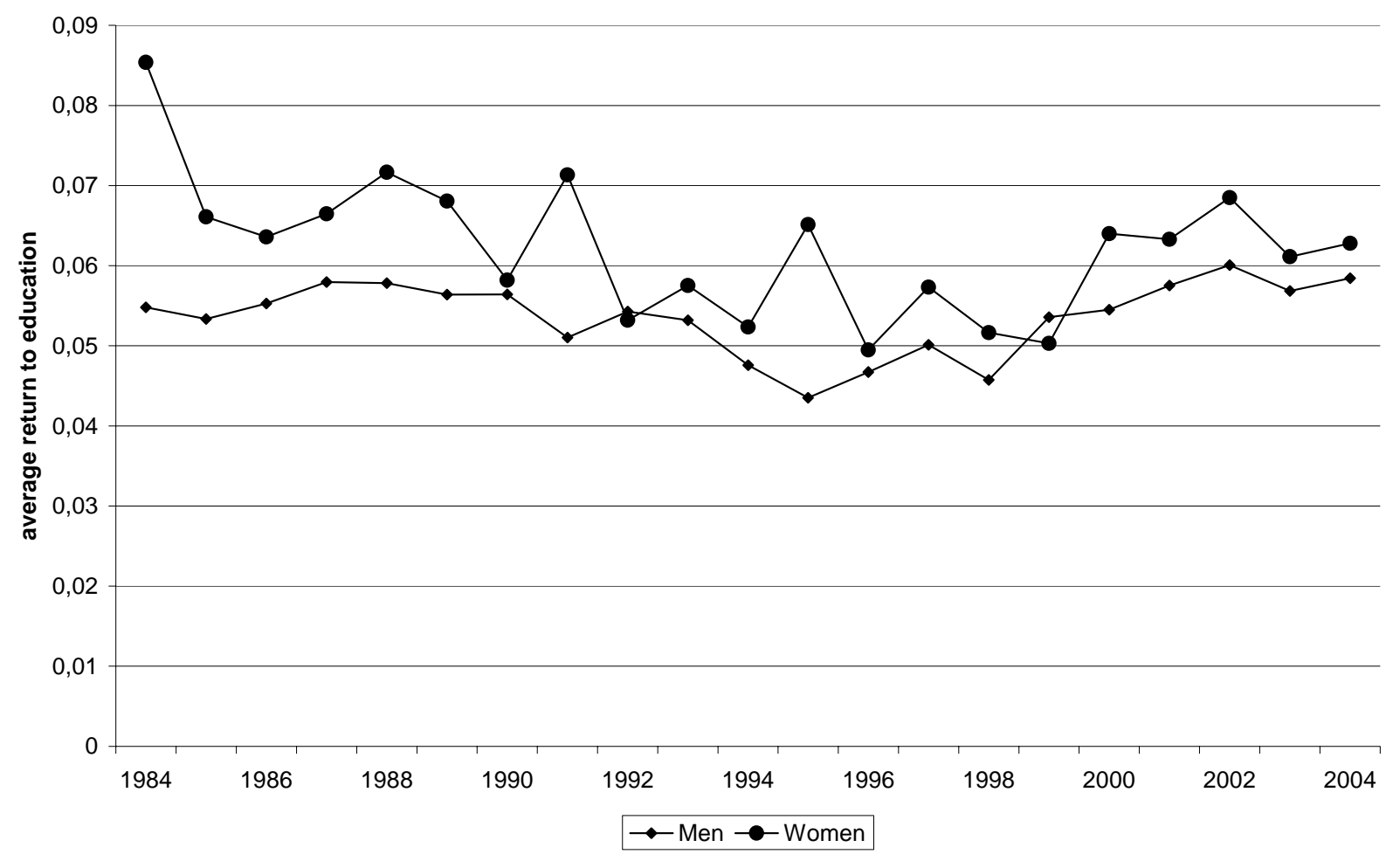

Source: SOEP (1984-2004); own computations.

Furthermore, figure 4 indicates that the gender gap in returns to education decreased over time, which is in line with findings from Ammermüller and Weber (2005), among others. Although women's returns to education are estimated as being higher in almost every year, the differences is insignificant since 1995. As a consequence of changes in the workplace organisations during the computer revolution, the labour services of women and men might have become better to substitute (see for instance Spitz-Oener, 2006) which in turn might be one reason for the equality of returns to education. Another possible reason could result from collective wage bargaining in Germany.

In a last step, the average returns to education are compared for four different birth cohorts. ${ }^{6}$ Each cohort is composed of eight years: people born between 1942 and

\footnotetext{
${ }^{6}$ We differentiate the cohorts based on relative birth cohort sizes and not relative to labour market cohort sizes because only the former are likely to be exogenous. Individuals change their educational attainment and labour market entry with respect to cohort size (Macunovich, 1999; Berger, 1989).
} 
1949, people born between 1950 and 1957, people born between 1958 and 1965 and those born between 1966 and 1973. The cohort boundaries are geared to cohort sizes (cp. figure A.1): The oldest cohort has low birth rates due to the 2nd World War and the post-war period. The second cohort $1950-57$ is of relatively constant size, whereas the third cohort 1958-65 is the "baby boom" cohort with strongly increasing cohort sizes peaking in 1964. Finally, the last cohort 1966-1973 is characterized by a sharply declining cohort size. However, in order to have cohorts with a sufficient number of observations, our estimations are restricted to birth cohorts that are older than 27 to 34 years, e.g. we estimate APE for cohorts born 1958-65 starting at the year 1992.

Time, cohort and life-cycle effects can not be easily disentangled empirically because it is impossible to observe two different birth cohorts at the same age and in the same year (Heckman and Robb, 1985). To empirically assess cohort effects in average returns to education in Germany different cohorts at the same age are compared at different points in times in the same labour market. Both figure 5 and 6 display estimation results for different cohorts at a given age (cp. tables A.6, A.7 and figure A.2 for details). We follow the development in the returns to education over a specific phase of the working life of a cohort for a period of five year. For example, all cohorts in figure 5 are observed at age 27-34. However, we do this for the cohort 1950-57 in 1984, for the cohort 1958-65 in 1992 and for the cohort 1966-73 in 2004.

Figure 5 reveals that the baby-boomer cohort has the lowest average return to education compared to the cohort before (1950-57) and the one thereafter (1966-73) where the former and the latter are characterised by lower and the latter even by sharply decreasing cohort sizes. A large cohort size seems to reduce the average return to education at young ages (27-38 years old). The higher supply of labour market entrants increases wage pressure in this group and decreases, ceteris paribus, their return to education which seems to be line with recent findings of Boockmann and Steiner (2006) and Steiner and Lauer (2001). The differences in the APEs are not significant from a statistical point of view.

Surprisingly, the differences in the APE fully disappear when the baby-boomer cohort is compared at older ages (35-46 years old) with other cohorts at the same age (see Figure 6). This might reflect the fact that large cohort sizes are absorbed by the labour market at later ages, i.e. cohort effects exist only for the young when they enter the labour market. In general, the findings hint at the existence of birth cohort effects for the young labour force that disappear when employees become older. This might stem from wage rigidity for incumbent workers and a higher degree of wage flexibility for entrants to the labour market (see for instance Gernandt and Pfeiffer, 2006a). 
Figure 5: Average Partial Effect of returns to education by birth cohorts at same age 27-38: CMI Approach

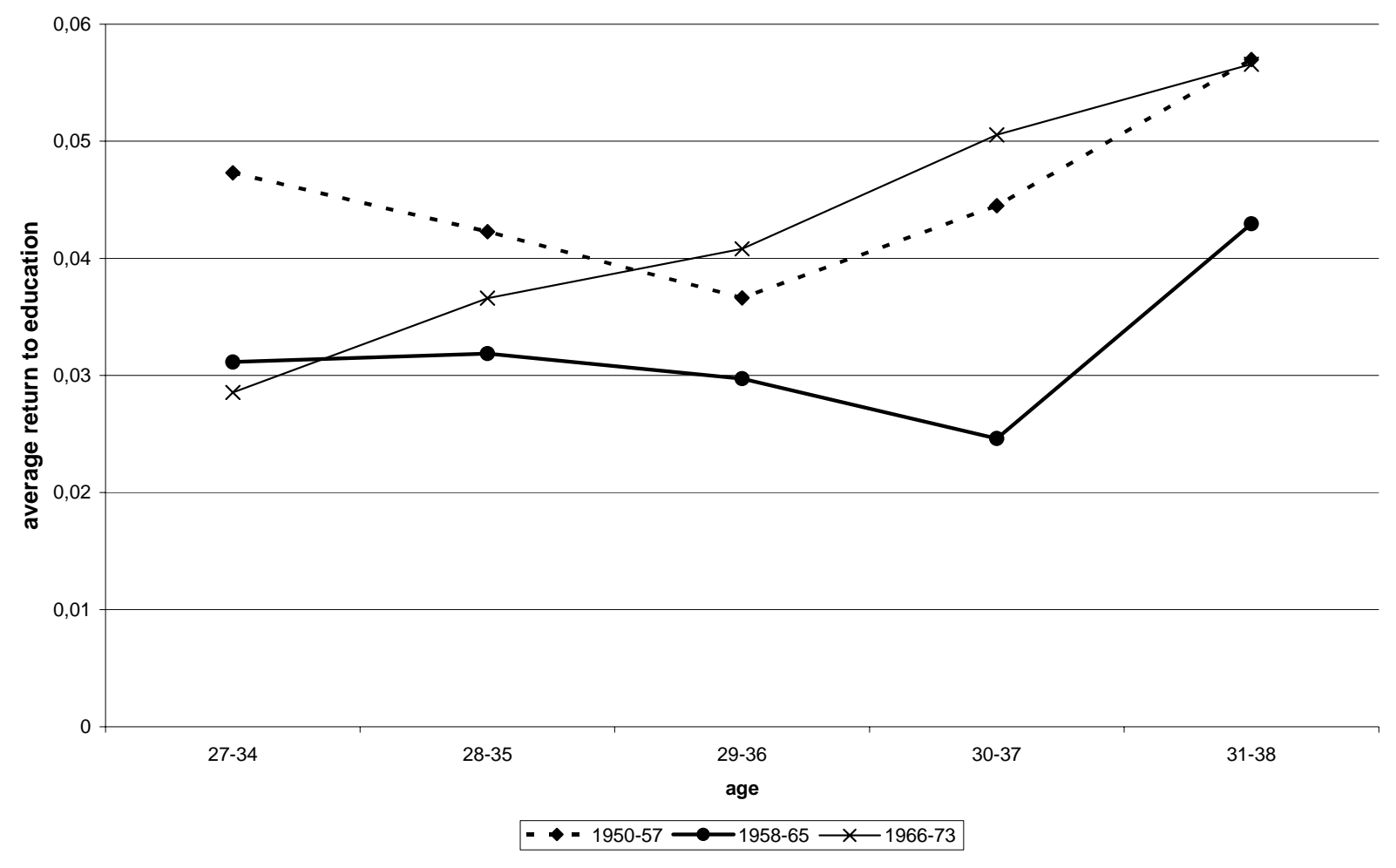

Source: SOEP (1984-2004); own computations.

Figure 6: Average Partial Effect of returns to education by birth cohorts at same age 35-46: CMI Approach

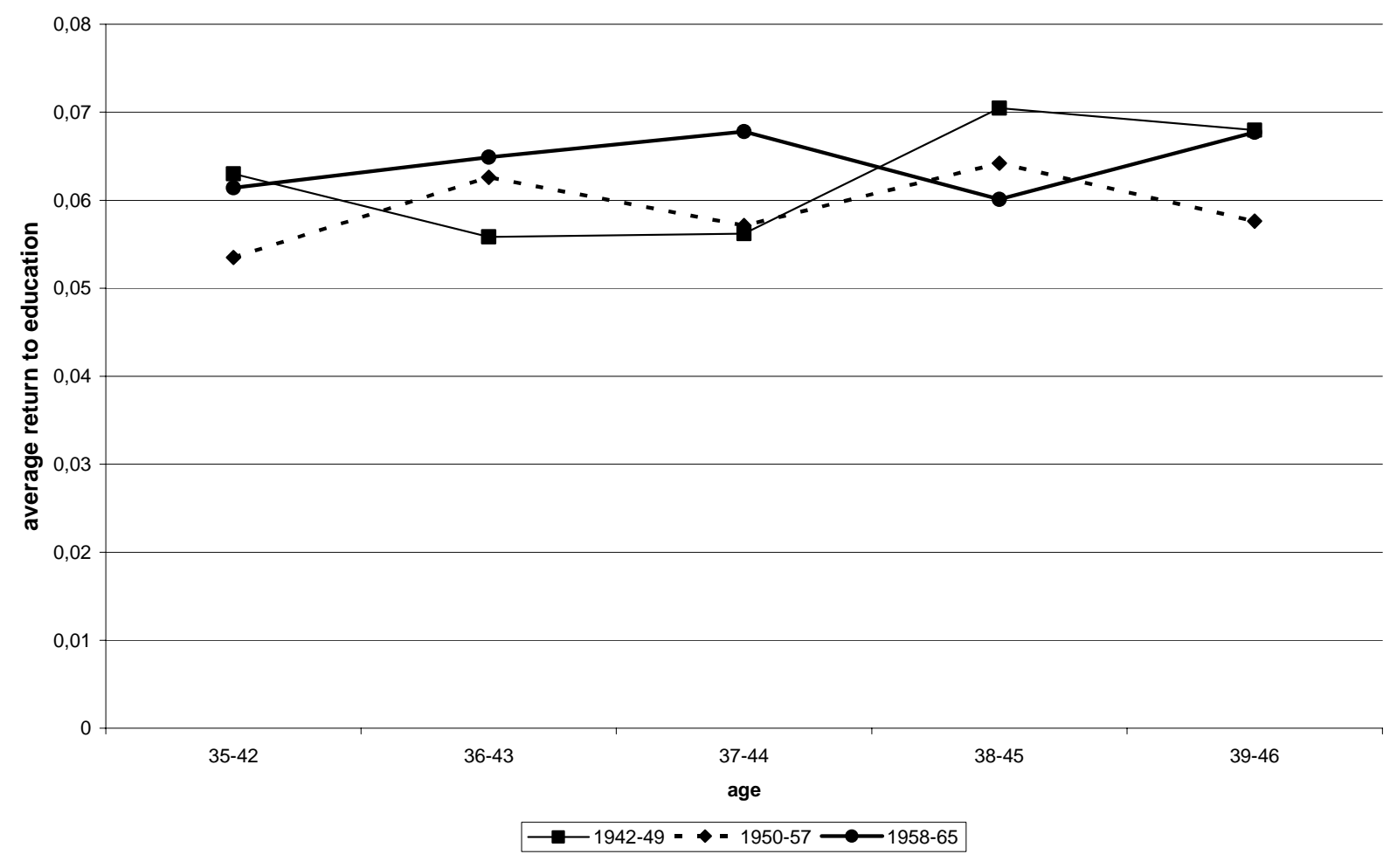

Source: SOEP (1984-2004); own computations. 


\section{Conclusions}

In Germany, graduates from the period of educational expansion in the sixties entered the labour market during the period of observation from 1984 to 2004. With a lag, this educational expansion contributed to skill upgrading of the labour force. For example, in our sample from the GSOEP the average years of education increased by roughly one year in this period. In order to tackle the issue of endogeneity of school choice and its heterogeneous returns we applied two estimation methods: Wooldridge's (2004) CMI approach and Garen's (1984) CF approach. The former method relies crucially on the conditional moment independence assumption which requires sufficient observable control variables. The latter method employs distributional assumptions and needs an exclusion restriction such that it can control for selection on unobservables.

Our findings based on Wooldridge's (2004) conditional mean independence and Garen's (1984) control function approach are that both approaches produce estimates of average returns to education that decrease until the late 1990s and increase significantly afterwards. During the period from 1984 to 2004 the estimated APE follows a roughly similar evolution pattern over time although standard errors from Garen's approach are relatively larger. According to the Wooldridge approach, returns to one additional year of education fell from 6.5 percent in 1984 to 4.9 percent in 1998. From 1998 onwards, we find increasing returns to education reaching a new local maximum of 6.4 percent in 2002 which is just below the overall maximum in 1984.

During the 1980s and early 1990s returns to education have been higher for women than for men, but the gender gap in returns vanished over time. According to our interpretation, decreasing returns to education for women are related to the strong female educational expansion and labour market participation. Furthermore, we find that the so called "baby boomer" cohort (workers born between 1958 and 1965) has the lowest average return to education compared to the cohort before and the one thereafter (the former is characterised by lower and the latter is characterised by sharply decreasing cohort sizes). This finding is in line with the literature on wages and cohort size in general (Macunovich, 1999). However, according to our estimates the effect exists only at young ages and disappears when employees become older. For a more detailed analysis of cohort and age effects in the process of educational expansion longer time periods and other data need to be taken into account.

In this study education is measured as years of schooling which might be problematic for a schooling system which is characterized by early ability tracking and general and vocational educational qualifications like the German one. To apply microeconometric methods to estimate the causal effect of different educational degrees on labour market outcomes and on the issue of over education should be a challenge for further research (e.g. Blundell et al., 2005, Maier et al., 2004). To dis- 
entangle the different influences on the evolution of returns to education, crosscountry comparisons with multi-level models are an interesting approach (e.g. Gangl, 2003, Van der Velden and Wolbers, 2003). Furthermore, research is necessary to dig deeper into potential indirect outcomes of educational expansion, taking into account the question of labour market regulations, employment and unemployment as well.

\section{References}

Acemoglu, D. (2002). “Technical Change, Inequality, and the Labor Market.” Journal of Economic Literature 40(1), 7- 72.

Ammermüller, A. and A. Weber (2005). "Educational Attainment and Returns to Education in Germany.” ZEW Discussion Paper \# 05-17. Mannheim.

Angrist, J., G. Imbens and D. Rubin (1996). "Identification and Causal Effects Using Instrumental Variables.” Journal of the American Statistical Association 90: 444-455.

Autor, D., L. Katz and M. Kearney (2006). "The Polarization of the U.S. Labor Market.” American Economic Review Papers and Proceedings 96(2): 189-194.

Becker, S. and F. Siebern-Thomas (2001). "Returns to Education in Germany: A Variable Treatment Intensity Approach.” IZA Discussion Papers \# 1046. Bonn.

Becker, G. and N. Tomes (1976). "Child Endowments and the Quantity and Quality of Children.” Journal of Political Economy 84: 143-162.

Berger, M. (1989). "Demographic Cycles, Cohort Size, and Earnings Growth: A Reexamination of the Evidence.” Journal of Political Economy 93: 561-573.

Blundell, R. and M. Costas Dias (2000).”Evaluation Methods for Non-Experimental Data.” Fiscal Studies 231(4): 427-468.

Blundell, R., L. Dearden and B. Sianesi (2005). "Evaluating the impact of education on earnings: Models, methods and results from the NCDS." Journal of the Royal Statistical Society Series A 168(3): 473-512.

Boockmann, B. and V. Steiner (2006). "Cohort Effects and the Returns to Education in West Germany.” Applied Economics 38: 1135-1152.

Card, D. (1995). "Using Geographic Variation in College Proximity to Estimate the Return to Schooling." In L. Christofides, E. Grant and R. Swidinsky (eds.), Aspects of Labour Market Behaviour: Essays in Honour of John Vanderkamp. Toronto: University of Toronto Press, 201-222.

Card, D. (1999). "The Causal Effect of Education on Earnings.” In O. Ashenfelter and D. Card (eds.), Handbook of Labor Economics 3. Amsterdam: NorthHolland, 1802-1863. 
Dustmann, C. (2004). "Parental Background, Primary to Secondary School Transitions, and Wages." Oxford Economic Papers 56(2): 209-230.

Erikson, R. and J. Goldthorpe (1992). The Constant Flux: A Study of Class Mobility in Industrial Societies. Oxford: Clarendon Press.

Erikson, R and J. Jonsson (1996). "Introduction. Explaining Class Inequality in Education: The Swedish Test Case." In R. Erikson and J. Jonsson (eds.), Can Education Be Equalized? The Swedish Case in Comparative Perspective. Boulder: Westview Press, 1-63.

Flossmann, A. and W. Pohlmeier (2006). "Causal Returns to Education: A Survey on Empirical Evidence for Germany." Jahrbücher für Nationalökonomie und Statistik 226(1): 6-23.

Franz, W. (2006). Arbeitsmarktökonomik. Heidelberg: Springer.

Franz, W. und F. Pfeiffer (2006). "Reasons for Wage Rigidity in Germany" LABOUR - Review of Labour Economics and Industrial Relations 20(2): 255-284.

Freeman, R. (1979). "The Effect of Demographic Factors on Age-Earnings Profiles.” Journal of Human Resources 14(3): 289-318.

Garen, J. (1984). ”The Returns to Schooling: A Selectivity Bias Approach with a Continuous Choice Variable.” Econometrica 52: 1199-1218.

Gangl, M. (2003). "Explaining change in early career outcomes: labour market conditions, educational expansion, and youth cohort sizes." In M. Gangl and W. Müller (eds.), Transitions from Education to Work in Europe. The integration of Youth into EU Labour Markets. Oxford: Oxford University Press, 251-276.

Gernandt, J. and F. Pfeiffer (2006a). „Einstiegslöhne bei unvollkommenen Arbeitsmärkten.“ Perspektiven der Wirtschaftspolitik 7(2): 147-172.

Gernandt, J. and F. Pfeiffer (2006b). "Rising Wage Inequality in Germany.” ZEW Discussion Paper \# 06-019. Mannheim.

Griliches, Z. (1977). "Estimating the Returns to Schooling: Some Econometric Problems.” Econometrica 45(1): 1-22.

Hanushek, E. (1992). “The Trade-Off Between Child Quantity and Quality.” Journal of Political Economy 100: 84-117.

Heckman, J. (1978). "Dummy Endogenous Variables in a Simultaneous Equation System.” Econometrica 46: 931-959.

Heckman, J. and X. Li (2004). "Selection Bias, Comparative Advantage and Heterogeneous Returns to Education: Evidence from China in 2000.” Pacific Economic Review 9(3), 155-171.

Heckman, J. and R. Robb (1985). "Using Longitudinal Data to Estimate Age, Period and Cohort Effects in Earnings Equations.” In W. Mason and S. Fienberg (eds.), 
Cohort Analysis in Social Research. Beyond the Identification Problem. New York: Springer, 137-150.

Heckman, J. and E. Vytlacil (2001). "Instrumental Variables, Selection Models and Tight Bounds on the Average Treatment Effects." In M. Lechner and F. Pfeiffer (Eds.), Econometric Evaluation of Active Labour Market Policies, Heidelberg: Physica, 1-21.

Heckman, J., L. Lochner, and P. Todd (2006). "Earnings Functions, Rates of Return and Treatment Effects: The Mincer Equation and Beyond.” In E. Hanushek and F. Welch (eds.), Handbook of the Economics of Education. North Holland: Amsterdam, 307-458.

Henz, U. and I. Maas (1995). "Chancengleichheit durch die Bildungsexpansion?” Kölner Zeitschrift für Soziologie und Sozialpsychologie 47(4): 605-633.

Ichino, A. and R. Winter-Ebmer (1998). "Lower and Upper Bounds of Returns to Schooling: An Exercise in IV Estimation with Different Instruments.” European Economic Review 43(4-6): 889-901.

Jochmann, M. and W. Pohlmeier (2004). "Der Kausaleffeekt von Bildungsinvestitionen: Empirische Evidenz für Deutschland.” In W. Franz, H. Ramser and M. Stadler (eds.), Bildungsökonomik. Wirtschaftswissenschaftliches Seminar Ottobeuren 33: Mohr Siebeck, 1-24.

Lauer, C. and V. Steiner (2001). "Returns to Human Capital in Germany - An Empirical Analysis." In C. Harmon, N. Nielsen and I. Walker (eds.), Returns to Education in Europe. Edgar Elgar: London, 125-146.

Ludwig, V. and F. Pfeiffer (2006). “Abschreibungsraten allgemeiner und beruflicher Ausbildungsinhalte. Empirische Evidenz auf Basis subjektiver Einschätzungen.“ Jahrbücher für Nationalökonomie und Statistik 226(3): 260-284.

Macunovich, D. (1999). “The Fortunes of One’s Birth: Relative Cohort Size and the Youth Labour Market in the United States.” Journal of Population Economics 12: 215-272.

Maier, M., F. Pfeiffer and W. Pohlmeier (2004). "Overeducation and Individual Heterogeneity.” In F. Büchel, A. de Grip and A. Mertens (eds.), Overeducation in Europe: Current Issues in Theory and Policy. Edward Elgar: Cheltenham, 133-152.

Müller, W. and M. Wolbers (2003). "Educational Attainment in the European Union: Recent Trends in Qualification Patterns.” In M. Gangl and W. Müller (eds.), Transitions from Education to Work in Europe. The integration of Youth into EU Labour Markets. Oxford: Oxford University Press, 23-62.

Müller, W. and D. Haun (1994): “Bildungsungleichheit im sozialen Wandel.” Kölner Zeitschrift für Soziologie und Sozialpsychologie 46(1): 1-42. 
Pischke, J. and T. van Wachter (2005). "Zero Returns to Compulsory Schooling in Germany: Evidence and Interpretation.” NBER Working Paper \# 11414. Cambridge, MA.

Schimpl-Neimanns, B. (2000). "Soziale Herkunft und Bildungsbeteiligung. Empirische Analysen zu herkunftsspezifischen Bildungsungleichheiten zwischen 19850 und 1989." Kölner Zeitschrift für Soziologie und Sozialpsychologie 52: 636-669.

Schuetz, G., H. W. Ursprung and L. Woessmann (2005). "Education Policy and Equality of Opportunity”, IZA Discussion Paper \# 1906. Bonn.

Spitz-Oener, A. (2006). "Technical Change, Job Tasks and Rising Educational Demands: Looking Outside the Wage Structure." Journal of Labor Economics 24(2): 235-270.

Statistisches Bundesamt Deutschland (2006). Statistisches Jahrbuch für die Bundesrepublik Deutschland. Wiesbaden: Statistisches Bundesamt.

Taber, C. (2001). "The Rising College Premium in the Eighties: Return to College or Return to Unobserved Ability?” Review of Economic Studies 68: 665-691.

Van der Welden, R. and M. Wolbers (2003). "The Integration of Youth into Labour Market: the Role of Training Systems and Labour Market Regulations.” In M. Gangl and W. Müller (eds.), Transitions from Education to Work in Europe. The integration of Youth into EU Labour Markets. Oxford: Oxford University Press, 186-211.

Walker, I. and Y. Zhu (2005). "The College Wage Premium, Overeducation, and the Expansion of Higher Education in the UK.” IZA Discussion Paper \# 1627. Bonn.

Willis, R. and S. Rosen (1979). "Education and Self-Selection” Journal of Political Economy 87: 7-36.

Wooldridge, J. (2002). Econometric Analysis of Cross Section and Panel Data. Cambridge: MIT Press.

Wooldridge, J. (2004). "Estimating Average Partial Effects under Conditional Moment Independence Assumptions." CEMMAP Working Papers CWP03/04. London. 


\section{Appendix}

Table A.1: Variable Definition

\begin{tabular}{|c|c|}
\hline Variable Name & Description \\
\hline log wage & Log gross hourly wage \\
\hline educyears & $\begin{array}{l}\text { Years of education: constructed with standard times for highest educational and } \\
\text { vocational degree obtained: no degree ( } 7 \text { years), lower secondary ( } 9 \text { years), in- } \\
\text { termediate secondary ( } 10 \text { years), technical secondary ( } 12 \text { years), higher secon- } \\
\text { dary ( } 13 \text { years), vocational training ( }+1.5 \text { years), vocational school (+2 years), } \\
\text { higher technical college ( }+3 \text { years), university ( }+5 \text { years) }\end{array}$ \\
\hline \multicolumn{2}{|l|}{ Demographics } \\
\hline age & Age in years \\
\hline age2 & Age squared \\
\hline female & Dummy for sex ( $1=$ female; $0=$ male $)$ \\
\hline \multicolumn{2}{|c|}{ Family Background } \\
\hline \multicolumn{2}{|c|}{ Aggregated CASMIN: Father’s Education } \\
\hline \multirow[t]{2}{*}{ fcasmin1ab } & Reference category: \\
\hline & $\begin{array}{l}\text { Inadequately completed elementary education or (compulsory) elementary educa- } \\
\text { tion }\end{array}$ \\
\hline fcasmin1c & Compulsory education plus vocational training \\
\hline fcasmin2ab & Secondary intermediate education, with/without vocational training \\
\hline fcasmin2c & Full secondary education (Abitur), with/without vocational training \\
\hline fcasmin3ab & University/ University of applied sciences \\
\hline \multicolumn{2}{|c|}{ Aggregated CASMIN: Mother’s Education } \\
\hline \multirow[t]{2}{*}{ mcasmin1abc } & Reference category: \\
\hline & $\begin{array}{l}\text { Inadequately completed elementary education or (compulsory) elementary educa- } \\
\text { tion; compulsory education plus vocational training }\end{array}$ \\
\hline \multirow[t]{3}{*}{ mcasmin2abc3ab } & Secondary intermediate education, with/without vocational training \\
\hline & Full secondary education (Abitur), with/without vocational training \\
\hline & University/ University of applied sciences \\
\hline
\end{tabular}


Table A.1: Variable Definition (continued)

\begin{tabular}{ll}
\hline \hline Variable Name & Description \\
\hline $\begin{array}{l}\text { Occupational Position Father } \\
\text { fbluecollar }\end{array}$ & Dummy (1= father blue collar; 0 else) \\
fwhitecollar & Dummy (1= father white collar; 0 else) \\
fselfemployed & Dummy (1= father self-employed; 0 else) \\
fcivilcervant & Dummy (1= father civil cervant; 0 else) \\
& \\
Place of Socialisation & \\
socrural & Dummy (1= rural socialisation, i.e. countryside; 0= urban socialisation, i.e. city, \\
& big town, small town) \\
Family Composition & \\
numbersiblings & Number of siblings \\
\hline \hline
\end{tabular}

Source: SOEP (1984-2004); own definitions. 
Table A.2: Summary Statistics

\begin{tabular}{lcccccc}
\hline \hline & \multicolumn{2}{c}{1984} & \multicolumn{2}{c}{1994} & \multicolumn{2}{c}{2004} \\
& Mean & Std. dev. & Mean & Std. dev. & Mean & Std. dev. \\
\hline log wage & 2.36 & 0.42 & 2.55 & 0.40 & 2.64 & 0.47 \\
educyears & 11.68 & 2.47 & 12.11 & 2.62 & 12.72 & 2.70 \\
age & 40.23 & 9.83 & 39.86 & 9.80 & 42.82 & 8.66 \\
age2 & 1714.85 & 811.94 & 1684.46 & 815.36 & 1908.67 & 740.83 \\
female & 0.35 & 0.48 & 0.38 & 0.49 & 0.42 & 0.49 \\
fcasmin1ab & 0.17 & 0.37 & 0.12 & 0.33 & 0.12 & 0.33 \\
fcasmin1c & 0.65 & 0.48 & 0.67 & 0.47 & 0.62 & 0.49 \\
fcasmin2ab & 0.09 & 0.28 & 0.10 & 0.30 & 0.13 & 0.33 \\
fcasmin2c & 0.03 & 0.18 & 0.03 & 0.17 & 0.03 & 0.18 \\
fcasmin3ab & 0.07 & 0.25 & 0.08 & 0.27 & 0.10 & 0.30 \\
mcasmin1abc & 0.12 & 0.33 & 0.16 & 0.37 & 0.21 & 0.41 \\
mcasmin2abc3ab & 0.49 & 0.50 & 0.48 & 0.50 & 0.46 & 0.50 \\
fbluecollar & 0.16 & 0.37 & 0.20 & 0.40 & 0.25 & 0.43 \\
fwhitecollar & 0.18 & 0.38 & 0.14 & 0.35 & 0.13 & 0.34 \\
fselfemployed & 0.11 & 0.31 & 0.12 & 0.32 & 0.11 & 0.31 \\
fcivilcervant & 1.73 & 1.77 & 1.75 & 1.73 & 1.75 & 1.67 \\
socrural & 0.40 & 0.49 & 0.38 & 0.49 & 0.38 & 0.49 \\
numbersiblings & 2.36 & 0.42 & 2.55 & 0.40 & 2.64 & 0.47 \\
\hline $\begin{array}{l}\text { N (number of ob- } \\
\text { servations) }\end{array}$ & 1,535 & & 2,070 & & 3,332 & \\
\hline \hline Source: SOEP & & & & & \\
& & & & & & \\
\end{tabular}

Source: SOEP (1984-2004); own computations. 
Table A.3: Average Partial Effect, 1984-2004: OLS, CMI, and CF compared

\begin{tabular}{|c|c|c|c|c|c|c|c|}
\hline & $\begin{array}{l}\text { OLS } \\
\text { coeff. }\end{array}$ & $\begin{array}{l}\text { OLS } \\
\text { s.e. }\end{array}$ & $\begin{array}{c}\text { APE (CMI) } \\
\text { coeff. }\end{array}$ & $\begin{array}{c}\text { APE (CMI) } \\
\text { s.e. }\end{array}$ & $\begin{array}{c}\text { APE (CF) } \\
\text { coeff. }\end{array}$ & $\begin{array}{c}\text { APE (CF) } \\
\text { s.e. }\end{array}$ & $\mathrm{N}$ \\
\hline 1984 & 0.073 & 0.004 & 0.065 & 0.004 & 0.079 & 0.073 & 1,535 \\
\hline 1985 & 0.064 & 0.004 & 0.059 & 0.004 & 0.032 & 0.042 & 1,591 \\
\hline 1986 & 0.068 & 0.004 & 0.060 & 0.004 & 0.086 & 0.173 & 1,674 \\
\hline 1987 & 0.069 & 0.004 & 0.062 & 0.004 & 0.092 & 0.047 & 1,767 \\
\hline 1988 & 0.069 & 0.004 & 0.064 & 0.004 & 0.084 & 0.040 & 1,787 \\
\hline 1989 & 0.067 & 0.003 & 0.062 & 0.004 & 0.070 & 0.045 & 1,909 \\
\hline 1990 & 0.063 & 0.003 & 0.059 & 0.004 & 0.059 & 0.030 & 1,996 \\
\hline 1991 & 0.062 & 0.003 & 0.060 & 0.004 & 0.037 & 0.030 & 2,108 \\
\hline 1992 & 0.063 & 0.003 & 0.057 & 0.004 & 0.050 & 0.028 & 2,090 \\
\hline 1993 & 0.060 & 0.003 & 0.056 & 0.004 & 0.066 & 0.028 & 2,111 \\
\hline 1994 & 0.057 & 0.003 & 0.051 & 0.003 & 0.055 & 0.023 & 2,070 \\
\hline 1995 & 0.058 & 0.003 & 0.053 & 0.004 & 0.061 & 0.026 & 2,066 \\
\hline 1996 & 0.054 & 0.003 & 0.049 & 0.004 & 0.048 & 0.025 & 2,049 \\
\hline 1997 & 0.058 & 0.003 & 0.054 & 0.003 & 0.071 & 0.024 & 2,003 \\
\hline 1998 & 0.054 & 0.003 & 0.049 & 0.003 & 0.050 & 0.022 & 2,140 \\
\hline 1999 & 0.058 & 0.003 & 0.054 & 0.003 & 0.065 & 0.023 & 2,161 \\
\hline 2000 & 0.065 & 0.002 & 0.059 & 0.003 & 0.103 & 0.022 & 3,958 \\
\hline 2001 & 0.064 & 0.002 & 0.060 & 0.003 & 0.090 & 0.021 & 3,954 \\
\hline 2002 & 0.067 & 0.003 & 0.064 & 0.002 & 0.103 & 0.029 & 3,682 \\
\hline 2003 & 0.063 & 0.003 & 0.059 & 0.003 & 0.118 & 0.030 & 3,509 \\
\hline 2004 & 0.063 & 0.003 & 0.061 & 0.003 & 0.117 & 0.032 & 3,332 \\
\hline
\end{tabular}

Source: SOEP (1984-2004); own computations.

Remark: Standard errors of APE (CMI) and APE (CF) are bootstrapped each with 500 repetitions. 


\begin{tabular}{|c|c|c|c|c|c|c|c|}
\hline & \multicolumn{2}{|c|}{ 1. Stage } & \multicolumn{4}{|c|}{ 2. Stage } & \multirow[b]{3}{*}{$\mathrm{N}$} \\
\hline & \multicolumn{2}{|c|}{ IV: Number of siblings } & \multicolumn{2}{|c|}{$\begin{array}{l}\text { Selection on unobserved } \\
\text { absolute earnings capac- } \\
\text { ity } v_{i} \text { and }\end{array}$} & \multicolumn{2}{|c|}{$\begin{array}{l}\text { Selection on unobserved } \\
\text { comparative earnings capac- } \\
\text { ity } v_{i} S_{i}\end{array}$} & \\
\hline & coeff. & s.e. & coeff. $\gamma_{1}$ & s.e. & coeff. $\gamma_{2}$ & s.e. & \\
\hline 1984 & -0.092 & 0.032 & 0.031 & 0.075 & -0.003 & 0.002 & 1,535 \\
\hline 1985 & -0.125 & 0.032 & 0.086 & 0.051 & -0.004 & 0.002 & 1,591 \\
\hline 1986 & -0.093 & 0.031 & 0.046 & 0.173 & -0.005 & 0.002 & 1,674 \\
\hline 1987 & -0.121 & 0.031 & 0.064 & 0.056 & -0.006 & 0.002 & 1,767 \\
\hline 1988 & -0.132 & 0.031 & 0.036 & 0.044 & -0.004 & 0.002 & 1,787 \\
\hline 1989 & -0.125 & 0.030 & 0.061 & 0.053 & -0.005 & 0.002 & 1,909 \\
\hline 1990 & -0.150 & 0.029 & 0.026 & 0.036 & -0.002 & 0.001 & 1,996 \\
\hline 1991 & -0.144 & 0.028 & 0.052 & 0.034 & -0.002 & 0.001 & 2,108 \\
\hline 1992 & -0.160 & 0.029 & 0.032 & 0.032 & -0.002 & 0.001 & 2,090 \\
\hline 1993 & -0.173 & 0.029 & 0.031 & 0.039 & -0.003 & 0.002 & 2,111 \\
\hline 1994 & -0.180 & 0.030 & -0.002 & 0.032 & 0.000 & 0.002 & 2,070 \\
\hline 1995 & -0.181 & 0.031 & 0.027 & 0.033 & -0.002 & 0.002 & 2,066 \\
\hline 1996 & -0.178 & 0.031 & 0.032 & 0.033 & -0.002 & 0.002 & 2,049 \\
\hline 1997 & -0.190 & 0.031 & 0.020 & 0.029 & -0.003 & 0.002 & 2,003 \\
\hline 1998 & -0.219 & 0.031 & 0.012 & 0.027 & -0.001 & 0.001 & 2,140 \\
\hline 1999 & -0.208 & 0.031 & 0.009 & 0.030 & -0.001 & 0.001 & 2,161 \\
\hline 2000 & -0.158 & 0.024 & 0.017 & 0.028 & -0.004 & 0.001 & 3,958 \\
\hline 2001 & -0.154 & 0.024 & 0.006 & 0.026 & -0.002 & 0.001 & 3,954 \\
\hline 2002 & -0.138 & 0.024 & 0.008 & 0.034 & -0.003 & 0.001 & 3,682 \\
\hline 2003 & -0.155 & 0.025 & -0.009 & 0.036 & -0.003 & 0.001 & 3,509 \\
\hline 2004 & -0.142 & 0.026 & -0.015 & 0.038 & -0.003 & 0.001 & 3,332 \\
\hline
\end{tabular}

Source: SOEP (1984-2004); own computations.

Remarks: 1. The first stage includes additional regressors like gender, age, rural socialisation, educational and occupational background of the parents.

2. The second stage includes additional regressors like years of education, gender, age, rural socialisation, educational and occupational background of the parents. The IV number of siblings is excluded.

3. Standard errors on the second stage are bootstrapped each with 500 repetitions. 
Table A.5: Average Partial Effect by gender, 1984-2004: CMI approach

\begin{tabular}{ccccccc}
\hline \hline & & Men & & & \multicolumn{3}{l}{ Women } & \\
& APE (CMI) & s.e. & $\mathrm{N}$ & APE (CMI) & s.e. & $\mathrm{N}$ \\
\hline 1984 & 0.055 & 0.005 & 1,004 & 0.085 & 0.007 & 531 \\
1985 & 0.053 & 0.004 & 1,021 & 0.066 & 0.009 & 570 \\
1986 & 0.055 & 0.005 & 1,056 & 0.064 & 0.008 & 618 \\
1987 & 0.058 & 0.005 & 1,113 & 0.066 & 0.007 & 654 \\
1988 & 0.058 & 0.004 & 1,135 & 0.072 & 0.008 & 652 \\
1989 & 0.056 & 0.004 & 1,210 & 0.068 & 0.008 & 699 \\
1990 & 0.056 & 0.004 & 1,230 & 0.058 & 0.008 & 766 \\
1991 & 0.051 & 0.004 & 1,286 & 0.071 & 0.007 & 822 \\
1992 & 0.054 & 0.004 & 1,276 & 0.053 & 0.007 & 814 \\
1993 & 0.053 & 0.004 & 1,297 & 0.058 & 0.008 & 814 \\
1994 & 0.048 & 0.004 & 1,275 & 0.052 & 0.007 & 795 \\
1995 & 0.043 & 0.005 & 1,266 & 0.065 & 0.007 & 800 \\
1996 & 0.047 & 0.004 & 1,230 & 0.049 & 0.007 & 819 \\
1997 & 0.050 & 0.005 & 1,221 & 0.057 & 0.006 & 782 \\
1998 & 0.046 & 0.004 & 1,300 & 0.052 & 0.006 & 840 \\
1999 & 0.054 & 0.004 & 1,313 & 0.050 & 0.006 & 848 \\
2000 & 0.055 & 0.003 & 2,369 & 0.064 & 0.004 & 1,589 \\
2001 & 0.058 & 0.003 & 2,343 & 0.063 & 0.004 & 1,611 \\
2002 & 0.060 & 0.003 & 2,164 & 0.069 & 0.005 & 1,518 \\
2003 & 0.057 & 0.004 & 2,049 & 0.061 & 0.005 & 1,460 \\
\hline \hline S005 & 0.058 & 0.004 & 1,938 & 0.063 & 0.005 & 1,394 \\
\hline
\end{tabular}

Source: SOEP (1984-2004); own computations.

Remark: Standard errors of APE (CMI) are bootstrapped each with 500 repetitions. 
Table A.6: Average Partial Effect by birth cohorts at same age 27-38: CMI approach

\begin{tabular}{ccccccccccc}
\hline \hline & \multicolumn{3}{c}{$1950-57$} & \multicolumn{3}{c}{$1958-65$} & \multicolumn{3}{c}{$1966-73$} \\
Age & Coeff. & s.e. & $\mathrm{N}$ & Coeff. & s.e. & $\mathrm{N}$ & Coeff. & s.e. & $\mathrm{N}$ \\
\hline $27-34$ & 0.047 & 0.007 & 394 & 0.031 & 0.009 & 593 & 0.029 & 0.006 & 866 \\
$28-35$ & 0.042 & 0.009 & 419 & 0.032 & 0.010 & 566 & 0.037 & 0.005 & 854 \\
$29-36$ & 0.037 & 0.008 & 443 & 0.030 & 0.008 & 584 & 0.041 & 0.006 & 821 \\
$30-37$ & 0.044 & 0.009 & 454 & 0.025 & 0.008 & 602 & 0.051 & 0.006 & 818 \\
$31-38$ & 0.057 & 0.006 & 464 & 0.043 & 0.007 & 609 & 0.057 & 0.006 & 753 \\
\hline \hline
\end{tabular}

Source: SOEP (1984-2004); own computations.

Remark: Standard errors of APE (CMI) are bootstrapped each with 500 repetitions.

Table A.7: Average Partial Effect by birth cohorts at same age 35-46: CMI approach

\begin{tabular}{ccccccccccc}
\hline \hline & \multicolumn{3}{c}{$1942-49$} & \multicolumn{3}{c}{$1950-57$} & \multicolumn{3}{c}{$1958-65$} \\
Age & Coeff. & s.e. & $\mathrm{N}$ & Coeff. & s.e. & $\mathrm{N}$ & Coeff. & s.e. & $\mathrm{N}$ \\
\hline $35-42$ & 0.063 & 0.007 & 351 & 0.053 & 0.006 & 520 & 0.061 & 0.005 & 866 \\
$36-43$ & 0.056 & 0.008 & 370 & 0.063 & 0.008 & 517 & 0.065 & 0.005 & 854 \\
$37-44$ & 0.056 & 0.008 & 385 & 0.057 & 0.006 & 490 & 0.068 & 0.005 & 821 \\
$38-45$ & 0.070 & 0.007 & 405 & 0.064 & 0.006 & 492 & 0.060 & 0.005 & 818 \\
$39-46$ & 0.068 & 0.008 & 387 & 0.058 & 0.008 & 485 & 0.068 & 0.006 & 753 \\
\hline \hline
\end{tabular}

Source: SOEP (1984-2004); own computations.

Remark: Standard errors of APE (CMI) are bootstrapped each with 500 repetitions. 
Figure A.1: Birth Cohort Size in West Germany

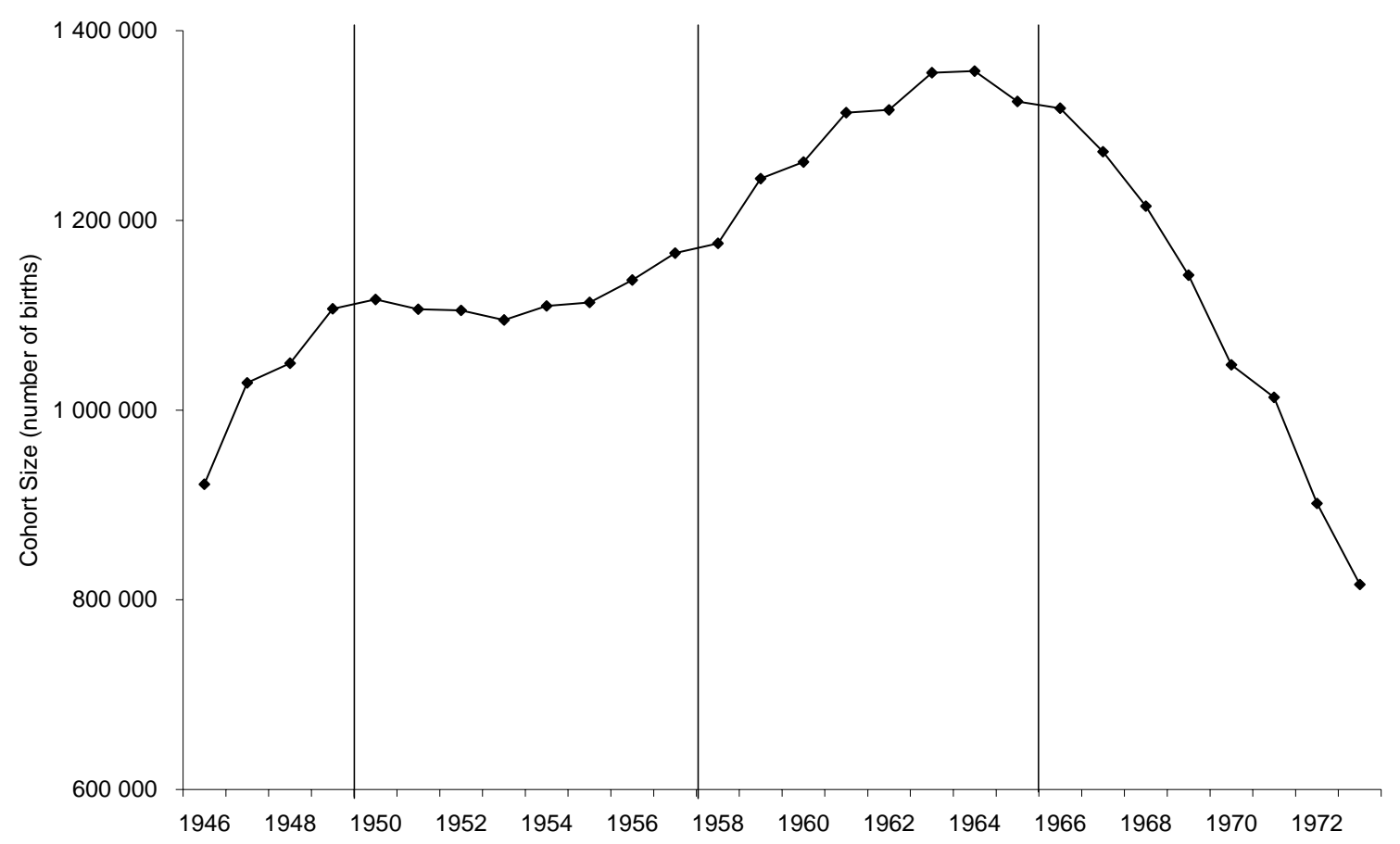

Source: Statistical Office Germany (2006)

Remark: The boundaries of birth cohort groups used in the analysis are marked by vertical lines. 
Figure A.2: Average Partial Effect by birth cohorts at same time: CMI approach

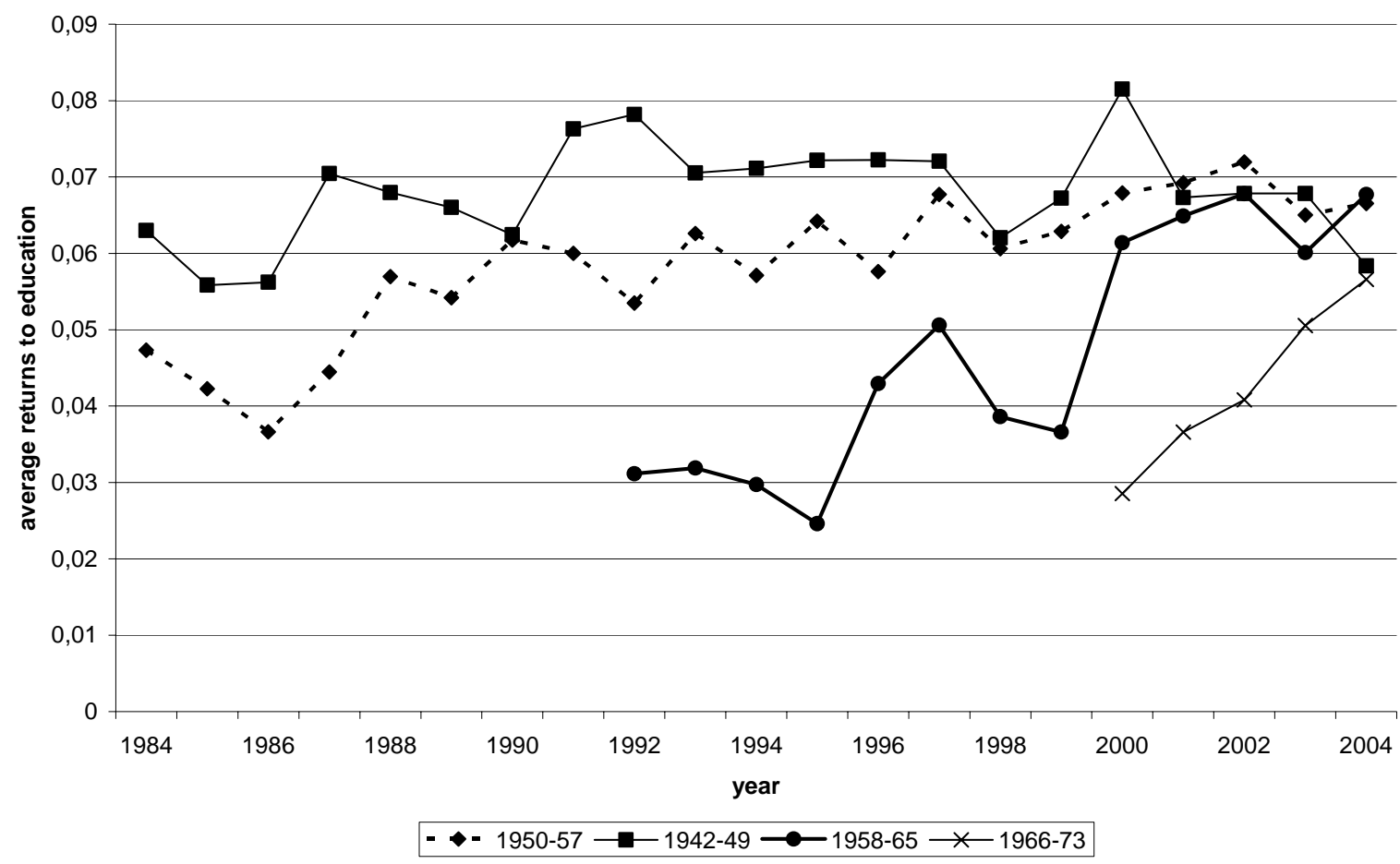

Source: SOEP (1984-2004); own computations.

Remark 1: The different starting points of the lines are a result of different cohort ages at a given time point and sample size problems. The lines begin when the birth cohort is 27-32 years old.

Remark 2: Reading the graph horizontally, we can compare the returns to education for older (left) and younger (right) birth cohorts at a given age but at different time periods. This procedure produces figures 5 and 6. 